\title{
On the Circular Supply Chain's Impact on Revenue Growth for Manufacturers of Assembled Industrial Products - a Conceptual Development Approach
}

\author{
Larsen, Samuel; Knudby, Torben; van Wonterghem, Jacques; Jacobsen, Peter
}

Published in:

2017 IEEE International Conference on Industrial Engineering and Engineering Management (IEEM)

Link to article, DOI:

10.1109/IEEM.2017.8290235

Publication date:

2017

Document Version

Peer reviewed version

Link back to DTU Orbit

Citation (APA):

Larsen, S., Knudby, T., van Wonterghem, J., \& Jacobsen, P. (2017). On the Circular Supply Chain's Impact on Revenue Growth for Manufacturers of Assembled Industrial Products - a Conceptual Development Approach. In 2017 IEEE International Conference on Industrial Engineering and Engineering Management (IEEM) IEEE. https://doi.org/10.1109/IEEM.2017.8290235

\section{General rights}

Copyright and moral rights for the publications made accessible in the public portal are retained by the authors and/or other copyright owners and it is a condition of accessing publications that users recognise and abide by the legal requirements associated with these rights.

- Users may download and print one copy of any publication from the public portal for the purpose of private study or research.

- You may not further distribute the material or use it for any profit-making activity or commercial gain

- You may freely distribute the URL identifying the publication in the public portal 


\title{
On the Circular Supply Chain's Impact on Revenue Growth for Manufacturers of Assembled Industrial Products - a Conceptual Development Approach
}

\author{
S. B. Larsen ${ }^{1}$, T. Knudby ${ }^{1}$, J. van Wonterghem ${ }^{1}$, P. Jacobsen ${ }^{2}$ \\ ${ }^{1}$ Center for Bachelor of Engineering Studies, Technical University of Denmark, Ballerup, Denmark \\ ${ }^{2}$ Department of Management Engineering, Technical University of Denmark, Kgs. Lyngby, Denmark \\ (sbla@dtu.dk)
}

\begin{abstract}
Materials scarcity, legislative compliance, and cost savings opportunities drive firms to take back used products from their customers for reuse, recovery, and recycling. For this purpose, firms implement circular supply chains. Although academia has given circular supply chain related topics considerable attention since the $1990 \mathrm{~s}$, the relationship between the circular supply chain and the firm's revenue growth remains under-researched. Using revenue growth theory, this study examines how the use of circular supply chains can grow the revenue of manufacturers of assembled industrial products (e.g. process equipment and engines). Findings show that the circular supply chain can increase revenue streams from the firm's existing markets, create market opportunities in new geographies, and provide access to market segments un-addressable with the firm's new products. The paper adds to understanding of the circular supply chain and provides research suggestions into the revenue potential inherent in circular supply chains.
\end{abstract}

Keywords - Circular economy, circular supply chain, closed-loop supply chain, revenue growth, reverse logistics

\section{INTRODUCTION}

The "take, make and waste" principle in the traditional linear economy makes materials scarcity one of the planet's great future challenges. An emerging concept that provides a solution to the scarcity challenge is the circular economy. The circular economy continuously reuses materials and resources [1]. In addition to solving the planet's materials scarcity problem, reuse offers manufacturers with a wide array of financially viable business opportunities [2-4].

The concept of the circular economy includes circular routes for complete products, for components and for materials. Among these circular routes are the sharing resources (e.g. cars and production equipment), repair of functioning products, remanufacturing and refurbishing of well-worn products, as well as recycling of used materials. For manufacturers of assembled industrial products such as engines and machines the circular economy translates into operating a well-functioning circular supply chain that includes processes of reverse logistics and product recovery. Fig. 1 illustrates the circular supply chain and how the circular supply chain relates to the firm's forward supply chain. The chain first reacquires used products from customers, transports these products to an internal sorting facility, sorts products in to recovery or waste streams, recovers the products sorted for recovery, and finally remarkets or reuses recovered items. The traditional term for this set of processes is the reverse supply chain [2]. However, with the emerging concept of the circular economy, this study will refer to reverse supply chains as circular supply chains.

The circular supply chain can contribute to the firm's bottom line profit. For example, [5] describe a circular supply chain that takes back used components for the purpose of recovery and reuse in the firm's service obligations for their installed base of functioning products. The example concerns reduction of the firm's operating costs by replacing the purchase or internal production of virgin components with reuse of recovered components. While academia has dealt with researching cost savings opportunities enabled by the circular supply chain, the impact on the firm's revenue is still under-researched. In particular the ways how the circular supply chain aid in revenue growth. The purpose of this study is to identify the links between the circular supply chain and the firm's revenue using revenue growth theory developed for the forward supply chain.

The study's domain is limited to manufacturers of assembled industrial products. Examples are

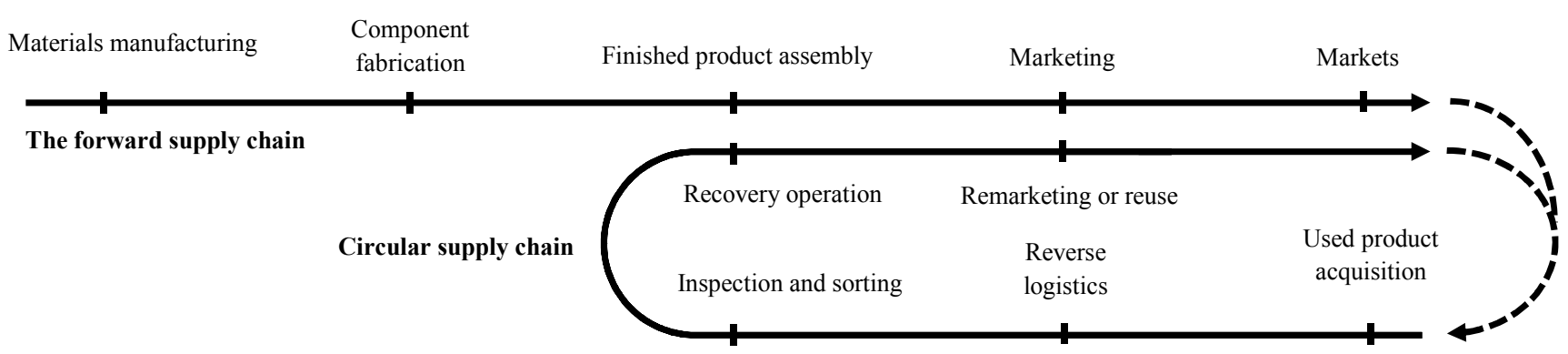

Fig. 1. The circular supply chain (adapted from [4]) 
manufacturers of processing equipment, engines, measurement equipment, and industrial white goods. This definition follows [6] and [7]. The manufacturers of assembled industrial products in focus of this study conduct end-product assembly in-house as well as some of the end-products' components. Remaining components and materials for in-house manufactured components are purchased from suppliers.

\section{LITERATURE REVIEW}

While Figure 1 illustrates the concept of the circular supply chain as it is applied in the present paper, the concept is closely related to the terms reverse logistics, product recovery management, reverse supply chain, and closed-loop supply chain (e.g. [2] and [8]). Literature contains numerous papers that examine aspects of circular supply chains. Examples are inventory management policies for items flowing through the circular supply chain, network design principles and solutions for the circular supply chains physical set-up, and pricing policies for recovered products. Common for most papers is that irrespective of a paper's research questions, the circular supply chain that forms the basis of the research is constituted by a set of processes that take back used products for the purpose of recovery and resale to the same set of customers from which used products are collected. In other words, the revenue that the circular supply chain provides the firm comes from one source: the firm's existing customers [9].

Extant literature does include papers that concern subjects differing from take-back and resale to the same customers. Some papers concern resale of components [10] and yet another group of papers concern resale of products to secondary markets [11]. Reference [3] conducts a conceptual identification of reverse supply chain enabled revenue streams, but develop the set of revenue streams directly from the reverse supply chain literature, while this study develops revenue streams using revenue growth theory from the traditional forward supply chain.

\section{METHODOLOGY}

To identify how the circular supply chain can contribute to the firm's revenue growth, the study seeks to identify how the firm can achieve new revenue through the use of the circular supply chain. An alternative methodology for this study is the structured literature review. This method relies on the assumption that all revenue streams achievable through the use if the circular supply chain are already captured in academic writings. This seems improbable as a number of papers (e.g. [12] and [13]) point out the scarce attention academia has given remarketing and development of markets for recovered products. Revenue opportunities may exist in industrial life even though academia has not (yet) described them. Using empirical methods would show only current revenue streams and perhaps those previously utilized in a chosen sample of firms. To ensure a higher degree of

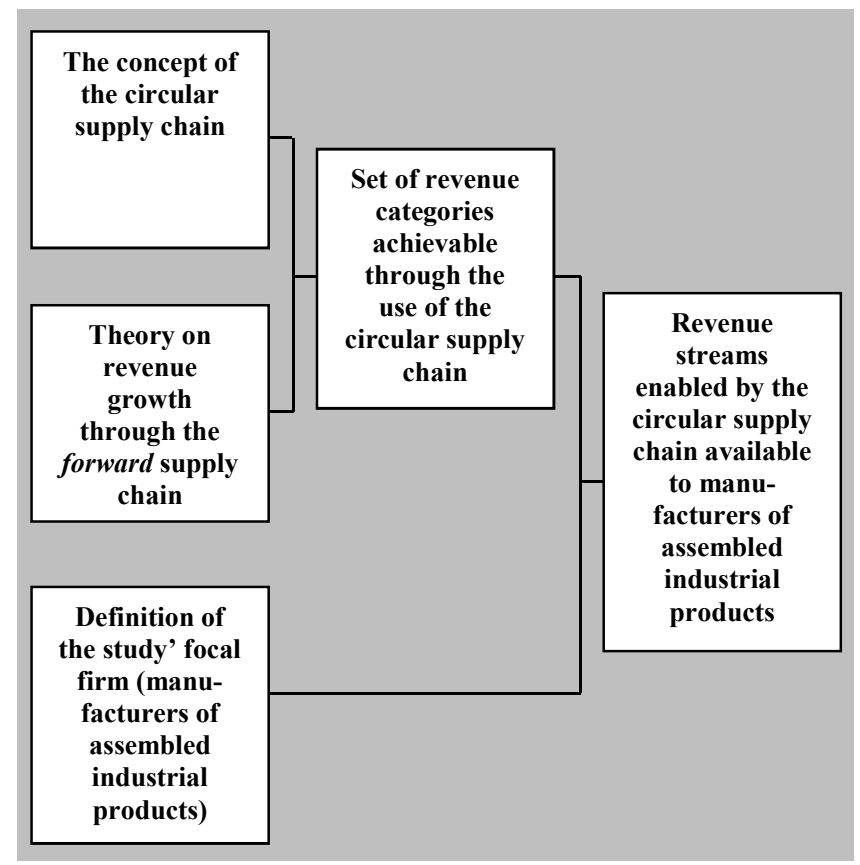

Fig.2. The methodology of the study

exhaustiveness, this study uses a conceptual approach that disaggregates the concept of circular supply chain enabled revenue growth. The following sections delineate the approach.

To identify which revenue streams the circular supply chain makes available to manufacturers of assembled industrial products, the study disaggregates the term "circular supply chain enabled revenue growth" using the following sequence: First, the study breaks down the term into a set of categories of revenue streams using revenue growth theory relevant for the forward supply chain; second, the study identifies the set of revenue streams within each revenue category. The total set of conceptually existing revenue streams available emerges from applying the proposed method.

For the purpose of the study a revenue stream enabled by the circular supply chain is defined as "a continuous flow of income received by the firm either directly from resale of used or recovered items processed in the firm's circular supply chain or indirectly through added virgin product sales enabled by the firm's circular supply chain". This definition follows the definition of reverse supply chain enabled revenue in [3]. The definition of the first type of revenue, "revenue received directly from sales of used or recovered items processed in the firm's circular supply chain ", has two constituent elements: a group of sellable items and a group of buyers. Every combination of a group of sellable items and a group of buyers constitutes a revenue stream. If a group of items has two distinguishable buyer groups then the firm has two potential revenue streams.

The study's conceptualization approach is illustrated in Fig. 2. The approach merges existing concepts and theory through the logic of "if $x$ and $y$, then $z$ ". The 
approach is referred to as conceptual modeling and lies within the category of analytical conceptual research ([14] and [15]). Beginning from the left in Fig. 2, the study merges the circular supply chain concept with revenue growth theory for the firm's forward supply chain to develop a set of categories of revenue achievable through a firm's circular supply chain. Then, the derived set of revenue categories is merged with the definition of the study's focal firm to reach a complete set of revenue streams available to the focal firm.

\section{RESULTS}

Although there are no established references on either circular or reverse supply chain theory ([16]), the conceptual definition of the circular supply chain as five connected processes by [2] appears prevalent in literature and is therefore chosen as the study's circular supply chain concept. The concept is described in the paper's introduction. For the theory on revenue growth achievable through the firm's forward supply chain the study chooses Ansoff's seminal paper from 1957 about growth strategies and diversification ([17]). In this paper, which concerns how a firm can diversify its product portfolio, Ansoff presents four revenue growth categories. These are 1) added sales of current products to existing market, 2) new products to existing markets, 3) current products to new markets, and 4) new products to new markets. In total, these four categories are exhaustive for organic revenue growth. To develop an equivalent set of revenue categories achievable through the firm's circular supply chain, the point of departure is these four categories.

The study assumes that the focal firm is currently only selling virgin products to existing markets. When implementing a circular supply chain the firm will have two new product groups added to their product portfolio. These are 1) products recovered in the circular supply chain and and 2) used products, which the circular supply chain takes back but does not recover. Selling used or recovered products to existing or new markets corresponds to the Ansoff categories No. 2 and 4, "New products to existing markets" and "New products to new markets". While Ansoff forms two categories by distinguishing between existing and new markets, this study forms two categories by separating used products from recovered products. These two categories are: 1) sales of used products to existing or new markets, and 2) sales of recovered products to existing or new markets. This separation is supported by [18]. The two new product groups (used products and recovered products) include not only complete endproducts, but also components and materials.

In addition to these two revenue categories, the circular supply chain can provide the basis for new revenue through added sales of virgin products to existing markets. This category corresponds to Ansoff's category no. 1, "added sales of current products to existing markets". Only Ansoff"s category No. 3, "current products to new markets", which in this study would be translated into virgin products to new markets, falls outside the scope of the study because it is not enabled by the circular supply chain, but instead the firm's forward supply chain.

In summation, three categories of revenue streams enabled by the circular supply chain conceptually exist. The left-hand column of Fig. 3 illustrates the three categories and the right-hand side explains the causal relation between the circular supply chain and revenue growth. The illustration of category A depicts a lateral and backward flow of used products, which can be sold to
Category A

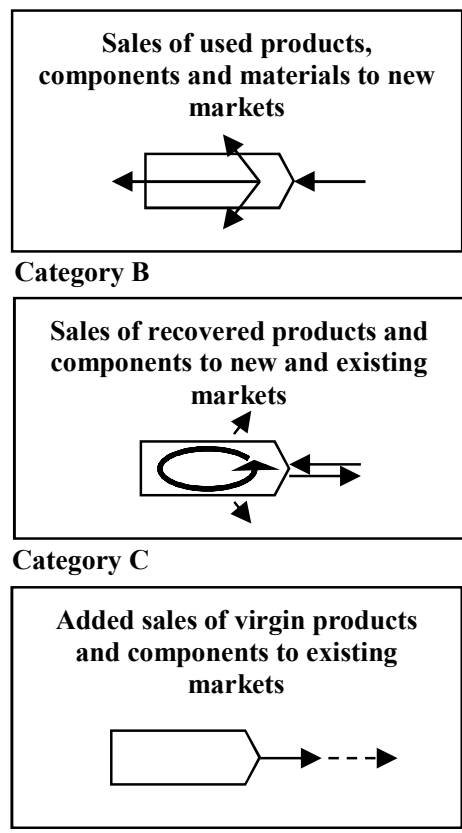

Overall causal relation between the $\mathrm{RSC}$ and new revenue in each category

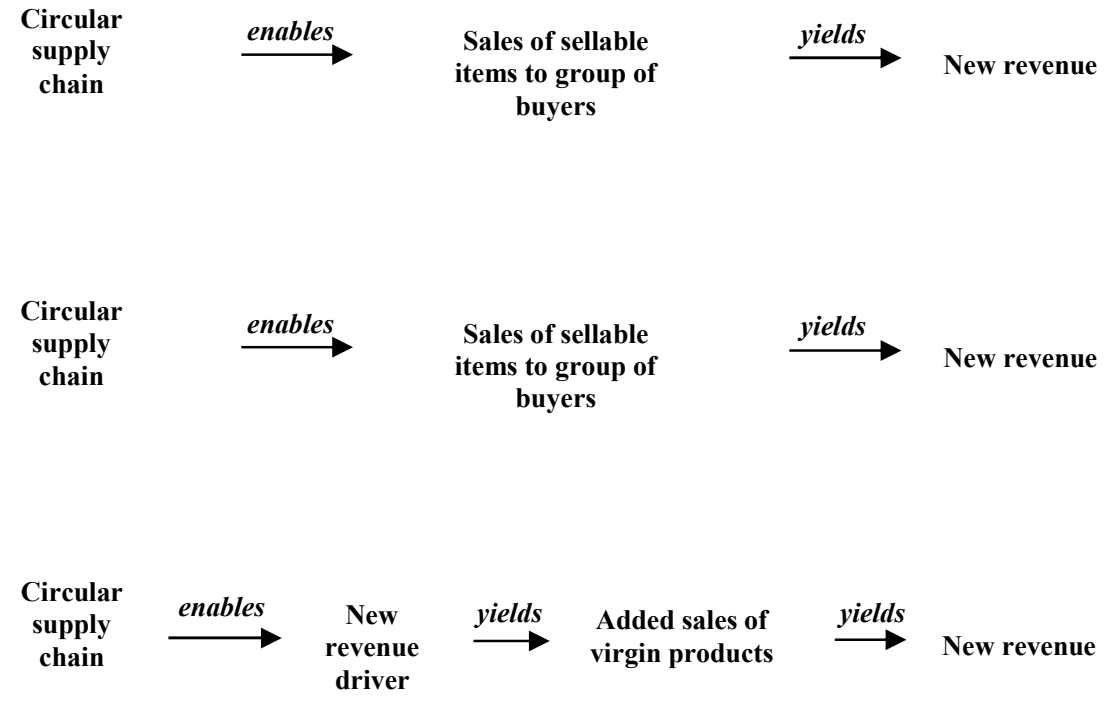

Fig. 3 - Revenue categories for the RSC 
buyer groups that are able to use either used end-products, used components, or used materials. The illustration of category B depicts the recovery process and lateral and forward flows of recovered products. The illustration of category $\mathrm{C}$ shows added sales of virgin products in the forward supply chain.

The following paragraph delineates how the study identifies revenue streams within each of the categories A, $\mathrm{B}$, and C. As described in the methodology section, any pairing of a group of sellable items with a buyer group constitutes a revenue stream. This definition applies in category A and B. To match groups of sellable items with buyer groups, the study asks two conceptual questions sequentially. The first question asks which groups of sellable items exist for the focal firm. Once the groups of sellable items are identified, the second question asks which groups of buyers exist for each group of sellable items. There may be one, two, or even more groups of buyers for each group of sellable items. For category A and $\mathrm{B}$ the causal relation is simple: The circular supply chain enables sales of sellable items to groups of buyers. In category $\mathrm{C}$, the group of sellable items is the firm's virgin products and the buyer group is the firm's current customers. According to [16], the circular supply chain enables added revenue through both retention of current customers and attraction of new customers, so the interesting question is not whether the circular supply chain enables added revenue from virgin product sales, but rather how. The causal relation in category $\mathrm{C}$, which Fig. 3 illustrates, relies on an intermediate factor labeled new revenue driver. A new revenue driver has two constituent elements: 1) The driver is enabled by the circular supply chain and 2) the driver yields new revenue through added virgin product sales.

The first question asked is which groups of sellable items conceptually exist if the focal firm were to implement a circular supply chain. The focal firm has up- and downstream boundaries. Within these boundaries are endproduct assembly and fabrication of some components. Remaining components and all materials are sourced. Given these boundaries five sellable items exist in category $\mathrm{A}$ and B: used end-products, used components, used materials, recovered end-products, and recovered components. One could argue for new revenue through

TABLE II

CIRCULAR SUPPLY CHAIN ENABLED REVENUE STREAMS CATEGORY A AND B

\begin{tabular}{|c|c|c|c|c|c|}
\hline \multirow[b]{2}{*}{$\begin{array}{l}\text { Cate- } \\
\text { gory }\end{array}$} & \multirow[b]{2}{*}{$\begin{array}{l}\text { Nature } \\
\text { of the } \\
\text { item }\end{array}$} & \multirow[b]{2}{*}{$\begin{array}{l}\text { In- or } \\
\text { outside } \\
\text { FSC* }\end{array}$} & \multicolumn{3}{|c|}{ Sellable item } \\
\hline & & & Materials & $\begin{array}{l}\text { Compo- } \\
\text { nents }\end{array}$ & $\begin{array}{l}\text { End- } \\
\text { products }\end{array}$ \\
\hline \multirow{2}{*}{ A } & \multirow{2}{*}{ Used } & Inside & A4 & A2 & \\
\hline & & Outside & A5 & A3 & A1 \\
\hline \multirow{2}{*}{ B } & \multirow{2}{*}{$\begin{array}{l}\text { Reco- } \\
\text { vered }\end{array}$} & Inside & & B2 & B1 \\
\hline & & Outside & & B4, B5 & B3 \\
\hline
\end{tabular}

*FSC: Forward supply chain
TABLE I

CIRCULAR SUPPLY CHAIN ENABLED REVENUE STREAMS CATEGORY A AND B

\begin{tabular}{|l|l|}
\hline A1 & Sales of used end-products to independent recovery firms (IRF) \\
\hline A2 & Sales of disassembled used components to original suppliers \\
\hline A3 & Sales of disassembled used components to IRFs \\
\hline A4 & Sales of used materials to original material suppliers \\
\hline A5 & Sales of used materials to independent recyclers \\
\hline B1 & $\begin{array}{l}\text { Sales of recovered end-products to the firm's primary market for } \\
\text { virgin products }\end{array}$ \\
\hline B2 & $\begin{array}{l}\text { Sales of recovered components to the firm's primary market for } \\
\text { virgin products }\end{array}$ \\
\hline B3 & Sales of recovered end-products to secondary markets \\
\hline B4 & Sales of recovered components to secondary markets \\
\hline B5 & $\begin{array}{l}\text { Sales of recovered components to direct competitors or related } \\
\text { manufacturers }\end{array}$ \\
\hline
\end{tabular}

sales of recovered materials. However, materials manufacturing (and recovery) lies outside the focal firm's upstream boundary.

The second question asks which buyer groups exists for each group of sellable item. The question is asked for firms in- and outside the focal firm's forward supply chain. Table 1 shows the complete set of revenue streams in category A and B. Streams are denoted as A1, A2, etc. Horizontally, the table shows the three different types of sellable items (materials, components, and end-products) that exist in the supply chain of the focal firm. Vertically, the figure shows the revenue category, the nature of the sellable item (used or recovered), and whether the group of buyers are located in- or outside the firm's forward supply chain. The table shows ten revenue streams. Table 2 lists and briefly describes each revenue stream.

The objective within category $\mathrm{C}$ is the identification of new revenue drivers that couple the circular supply chain with new revenue. The study assumes a correlation between a product's sales performance and market attractiveness, which means that a new revenue driver can drive new revenue by increasing a product's market attractiveness. According to [19] the market attractiveness of a product is determined by the customer's perception of the product's features, quality, price, and mix of services attached to the product. Customer perception of product features and quality is influenced by a product's brand image associations, which can translate directly into reasons to buy [20]. The circular supply chain enables firms to add services to the service mix and to refine their brand image by including environmental responsibility among the brand's associations. Adding services and refining a product's brand image both constitute new revenue drivers. Table 3 lists the consequent two revenue streams in category $\mathrm{C}$.

TABLE III

CIRCULAR SUPPLY CHAIN ENABLED REVENUE STREAMS CATEGORY C

\begin{tabular}{|l|l|}
\hline C1 & $\begin{array}{l}\text { Added sales of virgin products to existing customers through the } \\
\text { addition of RSC enabled services }\end{array}$ \\
\hline C2 & $\begin{array}{l}\text { Added sales of virgin products to existing customers through } \\
\text { brand image refinement }\end{array}$ \\
\hline
\end{tabular}




\section{DISCUSSION AND FUTURE RESEARCH SUGGESTIONS}

The study revealed 12 opportunities for how manufacturers of assembled industrial products can grow their revenue through the use of the circular supply chain. The study applies a conceptual approach, which future research could complement with empirical research. One question is whether revenue streams exists beyond the streams identified in this study. Another avenue of empirical research is the study of the factors that prohibit and advance the use of circular supply chain for growing revenue. The identification of factors and research that examines how and why factors impact the profitability of utilizing revenue streams. Operational issues such as reverse transportation, vehicle routing, network design, and inventory policies have received considerable attention. However, market related issues have yet to be fully understood. For example, customer willingness-topay for used and recovered products, issues of competition between original manufacturers and buyers of used products, the impact of market characteristics on willingness-to-pay (e.g. whether customer green-ness translates into higher prices), the impact of product resale on the firm's service revenue, the impact that the introduction of recovered product has on virgin product revenue, and whether circular supply chains can increase the firm's ability to compete on either price or differentiation.

\section{CONCLUSION}

The study shows that the circular supply chain can grow the firm's revenue by increasing the firm's revenue from existing markets, creating market opportunities in new geographies, and providing access to market segments that are currently un-addressable for the firm with its highpriced virgin products.

The study contributes to extant knowledge about the link between reverse and circular supply chain processes and the firm's revenue. More broadly, the study adds to understanding of the circular supply chain as a source of value creation. This view contrasts the traditional view of reverse processes as a costly nuisance necessary for handling returns or adhering to regulations.

\section{REFERENCES}

[1] Ellen MacArthur Foundation (2015), "Towards a circular economy: Business rationale for an accelerated transition" (ellenmacarthurfoundation.org)

[2] V. D. R. Guide, and L. N. Wassenhove. "Closed loop supply chains: an introduction to the feature issue (part 1)", Production and Operations Management 15, no. 3, pp. 345-350, 2006

[3] S. B. Larsen, and P. Jacobsen, "Revenue in reverse? An examination of reverse supply chain enabled revenue streams." International Journal of Physical Distribution \& Logistics Management 46, no. 8 (2016): 783-804.

[4] S. B. Larsen, D. Masi, P. Jacobsen, and J. Godsell, "How the reverse supply chain contributes to the firm's competitive strategy - a strategic alignment perspective", unpublished

[5] K. Inderfurth, and R. Kleber. "An advanced heuristic for multiple option spare parts procurement after end of production." Production and Operations Management, 22, no. 1 , pp. 54-70, 2013

[6] C. Karlsson, "The development of industrial networks: challenges to operations management in an extraprise", International Journal of Operations \& Production Management, Vol. 23, No. 1, pp. 44-61, 2003

[7] R. Geyer and Jackson, T., "Supply Loops and Their Constraints: The Industrial Ecology of Recycling and Reuse", California Management Review, Vol 46, No. 2, pp. 55-73, 2004

[8] M. Thierry, Salomon, M., Van Nunen, J., and Van Wassenhove, L., "Strategic Issues in Product Recovery Management", California Management Review, Vol. 37, No. 2, pp. 114-135, 1995

[9] S. B. Larsen, D. Masi, D. Feibert, P. Jacobsen, "How the reverse supply chain impacts the firm's financial performance: A manufacturer's perspective", unpublished

[10] M. Fleischmann, Van Nunen, J., and Gräve, B. "Integrating closed-loop supply chains and spare-parts management at IBM", Interfaces 33, no. 6, pp. 44-56, 2003

[11] M. Ferguson, M. Fleischmann, and G. Souza, "A Profit Maximizing Approach to Disposition Decisions for Product Returns", Decision Sciences 42, no. 3, pp. 773-798, 2011

[12] V.D.R. Guide Jr and Van Wassenhove, L., "OR FORUM the evolution of closed-loop supply chain research", Operations research, 57(1), pp. 10-18, 2009

[13] V.D.R. Guide Jr, and J. Li. "The potential for cannibalization of new products sales by remanufactured products." Decision Sciences 41, no. 3, pp. 547-572, 2010

[14] J. Meredith, "Theory building through conceptual methods", International Journal of Operations and Production Management, 13(5), pp. 3-11, 1993

[15] J. Wacker, "A definition of theory: research guidelines for different theory-building research methods in operations management", Journal of operations management, 16(4), pp. 361-385, 1998

[16] V. Jayaraman, Vaidyanathan, and Yadong Luo. "Creating competitive advantages through new value creation: a reverse logistics perspective." The Academy of Management Perspectives 21, no. 2, pp. 56-73, 2007

[17] I. Ansoff, "Strategies for diversification", Harvard business review 35 , no. 5, pp. 113-124, 1957

[18] S. Srivastava and R.Srivastava, "Managing product returns for reverse logistics", International Journal of Physical Distribution \& Logistics Management 36, no. 7 (2006): pp. 524-546, 2006

[19] P. Kotler, K. Keller, D. Manceau, and A. HémonnetGoujot. Marketing management. Vol. 14. Englewood Cliffs, NJ: Prentice Hall, 2015

[20] D. Aaker, Managing brand equity. Simon and Schuster, 2009. 